\title{
Peripheral Nerve Stimulation for Chronic Pain: A Systematic Review of Effectiveness and Safety
}

\author{
Standiford Helm (D) - Nikita Shirsat · Aaron Calodney • \\ Alaa Abd-Elsayed · David Kloth • Amol Soin · Shalini Shah • \\ Andrea Trescot
}

Received: June 22, 2021 / Accepted: August 9, 2021 / Published online: September 3, 2021

(C) The Author(s) 2021

\section{ABSTRACT}

Peripheral nerve stimulation (PNS) was the first application of neuromodulation. Widespread application of PNS was limited by technical concerns. Recent advances now allow the percutaneous placement of leads with ultrasound or fluoroscopic guidance, while the

Supplementary Information The online version contains supplementary material available at https:// doi.org/10.1007/s40122-021-00306-4.

S. Helm $(\bowtie) \cdot$ S. Shah

Department of Anesthesiology and Pain

Management, University of California, Irvine,

Orange, CA, USA

e-mail: drhelm@thehelmcenter.com

N. Shirsat

School of Medicine, University of California, Irvine, Orange, CA, USA

A. Calodney

Precision Spine Care, Tyler, TX, USA

A. Abd-Elsayed

Department of Anesthesiology and Pain

Management, University of Wisconsin School of

Medicine and Public Health, Madison, WI, USA

D. Kloth

OrthoCT, Danbury, CA, USA

A. Soin

Ohio Pain Clinic, Dayton, OH, USA

A. Trescot

Physician Partners of America, Orange Park, FL, USA transcutaneous powering of these leads removes the need for leads to cross major joints. This systematic review was written to assess the current status of high-quality evidence supporting the use of PNS for pain conditions treated by interventional pain physicians. The available literature on PNS, limited to conditions treated by interventional pain physicians, was reviewed and the quality assessed. Literature from 1966 to June 2021 was reviewed. The outcome measures were pain relief and functional improvement. One hundred and two studies were identified. Five randomized controlled trials (RCT) and four observational studies, all case series, met the inclusion criteria. One RCT was of high quality and four were of moderate quality; all four case series were of moderate quality. Three of the RCTs and all four case series evaluated peripheral nerve neuropathic pain. Based upon these studies, there is level II evidence supporting the use of PNS to treat refractory peripheral nerve injury. One moderate-quality RCT evaluated tibial nerve stimulation for pelvic pain, providing level III evidence for this indication. One moderatequality RCT evaluated surgically placed cylindrical leads for cluster headaches, providing level III evidence for this indication. The evidence suggests that approximately two-thirds of patients with peripheral neuropathic pain will have at least 50\% sustained pain relief. Adverse events from PNS are generally minor. A major advantage of PNS over spinal cord stimulation is 
the absence of any risk of central cord injury. The study was limited by the paucity of literature for some indications. No studies dealt with joint-related osteoarthritic pain.

Keywords: Peripheral nerve stimulation; Neuropathic pain; Neuropathy; Pelvic pain; Cluster headache

\section{Key Summary Points}

Chronic pain arising from peripheral nerve disorders is becoming more fully appreciated as a source of chronic pain.

Peripheral nerve stimulation has benefited from technological advances which allow its wider application.

There is a need for a systematic review, with inclusion of the underlying methodology supporting that review, of the high-quality literature supporting the use of peripheral nerve stimulation.

Five randomized controlled trials and four observational studies of high or moderate quality support the use of peripheral nerve stimulation.

The best evidence is for neuropathic pain.

\section{INTRODUCTION}

Popular conceptions of the cause of pain vary over time. In the early twentieth century, the sacroiliac joint was thought to be the primary source of low back pain [1]. With Mixter and Barr came the appreciation that the intravertebral disc was an important source of pain [2]. With Kuslich's intraoperative studies, the facet joint formed the third leg of this triad [3]. These studies focused primarily on the low back.

Only a small number of studies have focused on peripheral nerve disorders [4,5]. Following the publication of a comprehensive text on peripheral nerve entrapments [6], the role of peripheral nerves as a source of pain and as an avenue of treatment has become more widely recognized.

Neuromodulation of peripheral nerves to treat pain is an area of great intellectual activity. While spinal cord and deep brain stimulation have greater current public and clinical awareness than peripheral nerve stimulation (PNS), PNS antedates both. Melzack and Wall tested their gate theory of pain in 1965 by inserting electrodes into their own infraorbital foramina, generating paresthesia [7]. It is important to clarify that for the purposes of the Food and Drug Administration (FDA), PNS does not include stimulation of the dorsal root ganglion (DRG), although anatomically it is agreed that the DRG is located in the periphery. The proposed mechanism of action involves a gating mechanism whereby stimulation of large-diameter sensory neurons would "close the gate," reducing transmission of painful stimuli from small nociceptive fibers to the brain [8]. Stimulation is delivered from a system which is designed to be placed adjacent yet still remote from the nerve to selectively activate $A \alpha / \beta$ fibers while avoiding $\mathrm{A} \delta / \mathrm{C}$ fiber activation-a process commonly known as remote selective targeting. Typically, stimulation of mixed nerves at $100 \mathrm{~Hz}$ can selectively activate the largest sensory afferents; however, stimulation of mixed nerves at a low frequency such as $12 \mathrm{~Hz}$ can equally stimulate muscle efferent fibers, leading to remote selective targeting. In contrast to conventional "intimate" electrode placement, it has been hypothesized that percutaneous PNS systems may activate a greater proportion of large-diameter fibers while avoiding the unwanted activation of nociceptive afferents [79]. Shealy first applied spinal cord stimulation about 18 months after Wall and Melzack's studies, in March 1967 [9]. The initial experimentation with PNS used both open and percutaneous placement of leads [10]. In the mid1980s, surgically placed paddle leads were trialed. Around 1999, percutaneous leads began to be used for diagnoses such as occipital headaches [11].

PNS has now entered a fourth phase with the introduction of systems that provide power 
percutaneously to the lead directly over the site of implant. This major advancement allows clinicians to avoid placing a lead (or extension) across a joint, lowering the risk of lead fatigue and migration $[12,13]$. PNS has been applied for conditions including plexus injuries, mononeuropathies, post-amputation pain, back pain, sacroiliac joint pain, headache, facial pain, arm and limb pain, and joint pain [14]. It has also been used for postoperative pain, hyperactive bladder, and fecal incontinence.

The role of the current review is to assess the current status of the evidence supporting the use of neuromodulation of peripheral nerves to treat subacute or chronic pain, including treatment of cranial/facial pain, nerve entrapment/ injury, joint degeneration, or axial or radicular pain. This systematic review will assess the literature on PNS for nerve entrapment, joint pain, or axial or radicular pain up until June 2021.

\section{METHODS}

The methodology utilized in this systematic review followed the review process derived from evidence-based systematic reviews and metaanalysis of randomized trials and observational studies [15-30].

\section{Criteria for Considering Studies for this Review}

Indications which would not normally be treated by interventional pain management physicians, such as hyperactive bladder, acute pain, fecal incontinence, neurological disorders such as tremor, and psychological disorders are not covered by this review.

Only studies dealing with implanted devices were included. Only PNS, not peripheral nerve field stimulation, will be evaluated. PNS refers to the placement of a lead near a specific peripheral nerve. Peripheral nerve field stimulation (PNFS) refers to the placement of a lead subcutaneously in the general area of pain [31]. Percutaneous electrical nerve stimulation (PENS), in which multiple small acupuncturelike electrodes pierce the skin and provide stimulation [32], is not reviewed. Medicare has used the term "percutaneous electrical nerve stimulation" to describe PNS, confusing the issue [33].

PNS was first used for the occipital nerve [11]. Occipital nerve stimulation has been the subject of many systematic reviews showing effectiveness [34-40], so it is not covered in this review. Stimulation of other nerves for headache will be reviewed.

PNS for pelvic pain has been the subject of systematic reviews in the gynecologic literature $[41,42]$ and is included here, as interventional pain physicians regularly treat pelvic pain. Shah et al. also described the numerous techniques of PNS for chronic pelvic pain, particularly pudendal neuralgia [43].

Deer et al. published a comprehensive systematic review of spine neurostimulation nerve stimulation [44]. This review differs in that it includes databases not previously utilized and non-randomized studies, and excludes both occipital and peripheral nerve field stimulation.

Deer et al. and $\mathrm{Wu}$ et al. each published a systematic review of PNS $[45,46]$. The current review includes subsequent literature and provides a more detailed presentation of the underlying methodology.

\section{Types of Studies}

Randomized controlled trials (RCT).

Non-randomized observational studies, including cohort studies, case-control studies, cross-sectional studies, and case series.

Case reports and reviews were evaluated for adverse effects.

\section{Types of Participants}

Patients receiving peripheral nerve stimulators for the treatment of pain, excluding occipital nerve stimulation for headache.

\section{Types of Interventions}

Percutaneous PNS.

\section{Types of Outcome Measures}

The primary outcome measure was pain relief.

The secondary outcome measures were functional status improvement, change in 
psychological status, or a reduction in either opioid use or reliance on health care interventions.

\section{Literature Search}

Searches were performed from the following sources, limited to articles published in English:

1. PubMed from 1966 https://www.ncbi.nlm.nih.gov/pubmed.

2. Cochrane Library https://www.cochranelibrary.com/.

3. Google Scholar https://scholar.google.com/.

4. Embase https://www.embase.com.

5. Scopus https://www.scopus.com/.

6. Previous systematic reviews

7. Clinical Trials https://clinicaltrials.gov/.

8. Communication with investigators active in the field.

9. Bibliographies of reviewed papers were also examined.

The search period was from 1966 through June 2021.

\section{Search Strategy}

The following search terms were used with PubMed:

(()((peripheral nerve stimulation) AND ((meta-analysis [pt] OR randomized controlled trial $[\mathrm{pt}] \mathrm{OR}$ controlled clinical trial [pt] OR randomized controlled trials [mh] OR random allocation [mh] OR double-blind method [mh] OR single-blind method [mh] OR clinical trial [pt] OR clinical trials [mh] OR ("clinical trial" [tw]) OR ((singl* $[\mathrm{tw}]$ OR doubl* [tw] OR trebl* [tw] OR tripl* ${ }^{*}$ tw]) AND (mask* [tw] OR blind* [tw])) OR (placebos [mh] OR placebo* [tw] OR random* $\left.{ }^{*} \mathrm{tw}\right]$ OR research design [mh:noexp]) NOT (animals [mh] NOT human [mh])))) NOT (bladder)) NOT (stroke)) NOT (vagus)) NOT (deep brain).

\section{Data Collection and Analysis}

Two review authors independently, in an unblinded standardized manner, developed search criteria, searched for relevant literature, and selected the manuscripts.

\section{Selection of Studies}

Two review authors screened the abstracts of all identified studies against the inclusion criteria. All articles with possible relevance were then retrieved in full text for comprehensive assessment of internal validity, quality, and adherence to inclusion criteria.

\section{Inclusion and Exclusion Criteria}

RCTs with statistical analysis and with at least 20 patients in the study were included. Observational studies, including case-control, cohort, cross-sectional, or case-series design, were included if they reported on at least 20 patients. Reports without appropriate diagnoses, nonsystematic reviews, book chapters, letters to the editor, and case reports were excluded.

For any condition, if there were more than five randomized trials, non-randomized or observational studies were not utilized.

Methodological Quality or Validity Assessment The quality of each individual article used in this analysis was assessed by:

1. Cochrane Review criteria [26] (Table 1),

2. American Society of Interventional Pain Physicians (ASIPP) Interventional Pain Management techniques-Quality Appraisal of Reliability and Risk of Bias Assessment (IPM-QRB) for randomized trials [47] (Table 2), and

3. ASIPP Interventional Pain Management Techniques-Quality Appraisal of Reliability and Risk of Bias Assessment for Nonrandomized Studies (IPM-QRBNR) for nonrandomized and observational Studies [48] (Table 3).

Tables 1, 2, and 3 are shown in Appendix I, Supplementary Material.

Utilizing Cochrane review criteria of risk of bias, studies meeting the inclusion criteria with 
at least 8 of 12 criteria were considered high quality and 5-7 criteria were considered moderate quality. Those meeting fewer than five criteria were considered as low quality and were excluded.

Based on ASIPP criteria for randomized trials and non-randomized studies, the studies meeting the inclusion criteria scoring of 32-48 were considered high-quality trials, studies with scores between 21 and 31 were considered moderate quality, and studies scoring 20 or less were considered low quality and were excluded.

The Cochrane review criteria indicate that the primary analysis should only be on the results of RCTs and that if results from studies other than RCTs are included, the data from the observational studies should be analyzed separately and contrasted with the results of the RCT analysis [26]. More recently, the move has been to include all study types, including non-randomized studies, such as case series [49]. This review will both incorporate all available evidence and separate the discussion of the various study types.

\section{Data Extraction and Management}

Methodological quality assessment was performed by the authors, with groups of two authors reviewing multiple manuscripts. The assessment was carried out independently in an unblinded standardized manner to assess the methodological quality and internal validity of all the studies considered for inclusion. Any discrepancies in the methodological quality assessment were evaluated by a third reviewer and settled by consensus.

If there was conflict of interest with a reviewed manuscript, the involved author(s) did not review the manuscript for methodological quality assessment.

\section{Meta-Analysis}

If the literature search provided at least three randomized trials meeting the inclusion criteria and if they were clinically homogeneous for each modality and condition evaluated, a metaanalysis was performed.

\section{Compliance with Ethics Guidelines}

This article is based on previously conducted studies and does not contain any new studies with human participants or animals performed by any of the authors.

\section{Outcome Measurements}

Previously, the consensus was that at least a two-point change on a pain scale of $0-10$ was necessary to document a clinically meaningful change [50]. Because the body of evidence does not permit conclusions about the magnitude of change in either the numeric rating scale (NRS) or visual analog scale VAS that is clinically significant among chronic pain patients $[18,51]$, and given that $30-33 \%$ improvement has been recommended as a clinically relevant change $[26,52-54]$, this study will define clinically meaningful pain relief as a $30 \%$ reduction from baseline. Remission from chronic pain has recently been suggested to be defined as a pain score of $\leq 3.0$ on an 11-point scale for at least 6 months [55]; because the reviewed studies have not generally adopted this definition, it will not be used as an outcome measurement.

Clinically meaningful functional status improvement is $40 \%$ or more.

Short-term efficacy is defined as less than 6 months; long-term efficacy is defined as 6 months or longer.

\section{Grading of Evidence}

The grading of the evidence was performed using ASIPP's modification of the United States Preventive Services Task Force (USPSTF) criteria and other criteria [56-62].

Table 4 shows ASIPP's method of rating evidence, ranging from level I, consensus, at the bottom to level V, multiple RCTs, as the strongest level of evidence. Table 4 is found in Appendix I, Methodological Quality Tables, Supplementary Material. 


\section{DATA ANALYSIS}

Figure 1 shows a flow diagram of study selection as recommended by the Preferred Reporting Items for Systematic Reviews and Meta-Analyses (PRISMA) [63].

There were 819 studies considered for inclusion $[7,13,64-142]$. Of these, 61 studies were excluded from further review.

Table 5, List of Excluded Randomized and Non-randomized Studies, shows the reasons for exclusion.

Table 6 illustrates the characteristics of the eight RCTs and 12 observational studies considered for inclusion.

\section{Methodological Quality Assessment}

Table 7, Cochrane Review Bias Analysis, shows the bias analysis of the eight RCTS considered for review.

Table 8, The ASIPP IPM-QRB Analysis, shows the ASIPP bias and quality analysis for the eight RCTs.

Table 9, The ASIPP IPM-QRBNR Analysis for non-randomized studies, shows ASIPP's bias and quality analysis for the 11 non-randomized studies.

Of the eight RCTs and 11 observational studies considered for inclusion, three RCTs $[95,134,136]$ and eight observational studies $[66,98,103,104,113,116,121,142]$ were considered low quality on the appropriate ASIPP analysis and were excluded.

Of the five included RCTs, one [88] was of high quality and four $[64,131,132,135]$ were of moderate quality.

Of the four included observational studies, all of which were case series, all were of moderate quality [71, 74, 91, 99].

Tables 7, 8 and 9 are found in Appendix II, Data Results and Quality Assessment, Supplementary Material.

\section{Meta-Analysis}

There was insufficient homogeneity of the studies to permit a meta-analysis.

\section{Study Characteristics}

Table 10 shows the study characteristics of the five randomized trials and four case series evaluating PNS which were included for consideration.

Table 10 is found in Appendix III, Study Characteristics, Supplementary Material.

\section{RESULTS}

There are three RCTs and four case series evaluating the use of PNS to treat refractory peripheral nerve neuropathic pain, including complex regional pain syndrome (CRPS), nerve entrapment, and post-stroke pain. One RCT looked at cluster headache and one at pelvic pain.

Table 10, Summary of Study Results, provides an overview of these nine studies. Table 10 is shown in Appendix III, Study Characteristics, Supplementary Material.

Of the RCTs evaluating the treatment of peripheral nerve pain, Wilson et al. found $60 \%$ relief at 16 weeks [132]. Deer et al., using the Bioness StimRouter ${ }^{\circledR}$, found a mean pain reduction of almost $30 \%$ at 12 weeks, compared to a $2.3 \%$ reduction in the control group [64]. Gilmore, in the only high-quality RCT reviewed, found that $67 \%$ of the treated group had $\geq 50 \%$ relief, compared to $0 \%$ of the sham group. Interestingly, when the sham group crossed over to active treatment, only $17 \%$ had relief; this finding may be related to the technique of lead placement in this group [88]. Of the case series, Hassenbuch et al.'s study [99] was of moderate quality despite being 25 years old, a finding attributable to Dr. Hassenbuch's skills as an investigator. The study looked at CRPS patients, with $63 \%$ achieving at least 50\% relief over a mean follow-up of over 2 years. Eisenberg et al. [91], looking at peripheral nerve injury, also provided long-term follow-up, from 3 to 16 years, with $78 \%$ of patients having at least 50\% relief. Bouch et al. [74], looking at neuropathic pain, also provided long-term follow-up, with a minimum of 1 year and over half of the subjects providing reporting for more than 2 years. Two-thirds of the study's patients 
had at least 50\% relief. Colini Baldeschi et al. [71] looked at a patient population of which over one-half had CRPS, with a 6-month followup. Their patients had $61 \%$ mean relief, with $69 \%$ having at least $50 \%$ relief at 6 months.

Of the three RCTs evaluating relief of peripheral nerve neuropathic pain at a minimum of 3 months, two showed greater than $50 \%$ relief at the end point. The third showed a mean reduction of $27 \%$ versus essentially no relief in the control group.

The four case series provide documentation of long-term relief, up to 16 years. The case series generally support the RCTs, with greater than $50 \%$ relief in roughly two-thirds of the patients. A recent review of surgically implanted leads placed on peripheral nerves for treatment of CRPS over a 30-year time frame, documenting the experience at the Cleveland Clinic from 1990 to 2017, showed a mean 25\% relief at 12 months [138]. This lower level of relief may reflect both the problems faced by earlier CRPS studies with appropriate diagnosis of the syndrome [143] and the potential complications associated with surgically implanted leads and generators.

Of the two remaining RCTs, Schoenen et al. [131] showed that $67 \%$ of treated cluster headache attacks were controlled with surgically implanted cylindrical leads. Istek et al. [135] found that stimulating the tibial nerve for 30 min once a week for 12 weeks provided greater than $50 \%$ relief of pelvic pain.

\section{Levels of Evidence Supporting the Use of Peripheral Nerve Stimulation}

One high-quality RCT and two moderate-quality RCTs documented the efficacy of PNS in treating refractory peripheral nerve neuropathic pain. Therefore, there is level II evidence supporting PNS in the treatment of refractory peripheral nerve neuropathic pain. Four moderate-quality case series reports corroborate the findings of the RCTS and provide documentation of long-term, multiple-year relief.

As there is one moderate-quality RCT supporting the use of PNS for the treatment of cluster headaches, there is level III evidence for the use of PNS to the sphenopalatine ganglion in the treatment of cluster headache.

As there is one moderate-quality RCT supporting the use of PNS to the tibial nerve for the treatment of pelvic pain, there is level III evidence for the use of PNS in the treatment of pelvic pain.

\section{COMPLICATIONS}

Generally, PNS is safe. The early cuff and paddle leads, which required open surgical dissection for proper placement, had a high incidence of scarring and concomitant nerve damage, limiting adoption of PNS [65]. The current circular percutaneous leads have eliminated that problem. Ishizuka et al. found that these earlier systems also had problems with migration, infection, and the need for revision [144]. McJunkin found that $15 \%$ of these early systems needed to be explanted [145].

Chmiela et al. reported the complications seen in their 27-year history of surgically placed PNS leads for CRPS [138]. This review, like much of the early CRPS literature, did not show efficacy of the procedure in part because of the difficulty in diagnosing CRPS. Their experience showed that explanation occurred in 32 of 165 patients. Lack of efficacy was the reason for explanation in $50 \%$ of cases, while infection was the cause in another $28 \%$. The remaining $22 \%$ were divided between end of battery life, device discomfort, lead migration, and one case of motor loss.

Warner et al. described their 13-year history of PNS, reviewing 72 patients who underwent surgical implantation [142]. This study was felt to be of low quality in terms of documenting the efficacy of PNS, but the focus of the paper was on complications and indications rather than efficacy. Warner et al. found that 20 of 72 patients required explanation. Of these, five were explanted for infection, one for lead erosion, and four for resolution of pain. Seventeen patients required revision, nine for lead migration, five for device malfunction, five for lead or anchor erosion, and four for infection. Of note, all of Warner et al.'s procedures were done using devices designed for spinal cord stimulation, 
with none using current technology designed for spinal cord stimulation.

Eldabe et al., in a review of complications of spinal cord and peripheral stimulation, found lead migration to be the primary concern [146].

Lead fracture is a rare occurrence. Wilson reported a retained lead fragment which had no clinical significance [132]. Choi et al. reported lead fracture from a lead crossing a large joint [147]. Current stimulator systems, in which leads do not cross joints, markedly reduce the risk of lead fracture.

Pain related to an internal pulse generator has been a major concern, with Eldabe documenting up to $25 \%$ of patients complaining of pain related to the generator implant site. Currently available PNS systems have external generators, eliminating this problem. Infection and erosion, which were already rare, have now become even rarer complications because of the smaller incisions and the percutaneous approaches utilized. Gilmore et al. found no serious adverse events in their study [145]. Of their 22 study-related events, 21 were skin irritation or redness from the bandage or pain due to implantation or stimulation. The one moderate event was pain from stimulation, which resolved by reprogramming. Five leads were suspected of being fractured during removal and were monitored, with no clinical sequelae. The infection rate in this cohort was documented as $0 \%$. Deer et al. similarly reported no serious device-related adverse events [148]. Their adverse effects were rash, redness, and soreness related to the adhesive from the electrode patch. PNS systems target nerves outside the spinal canal, and therefore remove the risk of spinal cord damage associated with spinal cord stimulators.

\section{DISCUSSION}

PNS has been an area of interest since 1967, when Wall and Sweet, applying the gate theory of pain, first stimulated peripheral nerves [7]. Early adaptation of PNS was limited because of technical issues, including scarring, and because of the interest in spinal neuromodulation. Further, in the 1980s and 1990s, pain control using fluoroscopically guided injection techniques was an area of great intellectual interest. Over the last five decades, we have experienced an explosion of studies evaluating the utility of PNS for a variety of "difficult-to-treat" pain indications, inclusive of cephalgias, CRPS, and post-amputation pain. It is important to review these studies for the reader to appreciate the efficacy and duration of relief. While conventionally implanted percutaneous leads have been the dominant mechanism of stimulation, certainly the newer, smaller short-term wearables demonstrate some promise. In these newer devices, sustained relief has been reported, although the exact mechanism still alludes us. We will review the published data of the more recent advancements in PNS over the past three decades.

In 1996, Hassenbusch et al. [95] published the first moderate-quality case series, evaluating surgically applied plate electrodes to major peripheral nerves for CRPS, with 63\% experiencing good or fair relief over follow-up of up to 4 years. Twenty percent returned to some form of work. No further high- or moderate-quality studies were done evaluating PNS until 2004, when Eisenberg et al. [87] presented a case series looking at cuff and paddle leads placed over the involved nerves. With a follow-up of between 3 and 16 years, $78 \%$ of the peripheral nerve injury patients had greater than $50 \%$ relief and no need for analgesics.

In 2013, Schoenen et al. [127] published an RCT used minimally invasively implanted leads into the sphenopalatine fossa for cluster headache, with $68 \%$ of patients achieving $\geq 50 \%$ reduction of either pain in treated attacks or the frequency of attacks over a 12-month period.

Istek et al. [131] published an RCT in 2014 evaluating tibial nerve stimulation for $30 \mathrm{~min}$ followed by removal, repeated weekly for 12 weeks, for pelvic pain. At 6-month follow-up, patients had a mean $55 \%$ reduction in pain.

Shoulder and upper extremity pain have also been successfully treated with PNS. Wilson et al. [128] published an RCT in 2014 evaluating the treatment of hemiplegic shoulder pain after stroke, stimulating the axillary nerve with $6 \mathrm{~h}$ of daily stimulation for 3 weeks. At 4 months, there was a $60 \%$ reduction in shoulder pain. 
Deer et al. [60] in 2016 published an RCT evaluating percutaneously implanted stimulators for peripheral nerve pain, with a mean reduction of pain of $27 \%$ at 3 months.

In 2017, Bouche et al. [70] presented a case series of ultrasound-guided percutaneous stimulation of the upper extremity for neuropathic pain, with $65 \%$ of patients experiencing greater than 50\% relief after at least 1 year. Both CRPS and peripheral nerve injury patients responded to treatment.

Perhaps the greatest strides with PNS have been made for CRPS patients. In 2017, Colini Baldeschi [67] published a case series of peripheral nerve injury, including CRPS, with an ultrasound-implanted lead. At 6 months, the mean pain relief was $61 \%$, and $69 \%$ had at least $50 \%$ pain relief. Gilmore et al. [84], in the only high-quality study reviewed, published an RCT in 2020 looking at pain in amputees, providing ultrasound-guided placement of percutaneous leads with stimulation for 8 weeks, at which time the leads were removed. Of the treated group, $67 \%$ had $\geq 50 \%$ relief at 12 months, versus $0 \%$ of the sham group.

These nine studies provide level II evidence for neuropathic pain, including CRPS, and level III evidence for tibial nerve stimulation for pelvic pain and sphenopalatine ganglion stimulation for cluster headaches. The level of evidence for neuropathic pain is supported by both RTCs and case series. RCTS provide high-quality evidence of efficacy, but by their nature are limited to relatively short-term results, up to 1 year. Case series, on the other hand, can provide evidence of efficacy extending out a decade or more. Combined, these two sources provide powerful evidence of the effectiveness of PNS.

Further studies are needed supporting the use of PNS for osteoarthritic or post-surgical joint or low back pain. Gilmore et al.'s preliminary study of stimulation of the medial branches of the dorsal rami of the nerve roots for low back pain was excluded from this review because the enrolled population was too small [97]. However, it is important to comment that long-term follow-up at 12 months demonstrated that $67 \%$ of enrolled subjects endorsed a $63 \%$ reduction in low back pain intensity after a 30-day trial of the externalized wearable stimulator, irrespective of etiology of low back pain. Deer et al.'s subsequent study using the same methodology was also excluded because the enrolled population was too small and because of the extent of industry involvement [140]. However, these findings are supported by several other reports of simulation of other nerves which are of interest even though they did not meet the inclusion criteria. Elahi and Reddy, along with Wilson et al., Kurt et al., Manzi et al. and Mansfield and Desai, found PNS to be effective in treating shoulder pain $[68,72,76,109,110]$. These multiple studies suggest that there is a neuropathic component to back or joint pain which is responsive to PNS. Their findings highlight the extent of the need for high-quality studies confirming the role of PNS in treating joint or back pain.

Two major systematic reviews authored by $\mathrm{Xu}$ et al. [44] and Deer et al. [45] agree on several key aspects of the level of evidence for PNS for the indication of cluster headache, shoulder pain, and mononeuropathies (level II evidence). These reviews diverge, however, on the level of evidence for migraine (level I by Xu vs. beneficial by Deer) and pelvic pain (level II by $\mathrm{Xu}$ and level III by Deer). These findings suggest that many more high-quality RCTs are needed to form more consensus recommendations for these indications.

The mechanism by which PNS works is unclear, but the prevailing mechanism is thought to follow Wall and Melzack's gating theory in which activation of the large-diameter sensory fibers inhibits transmission of small-diameter nociceptive afferents. Finch et al. [65] performed a high-quality double-blind analysis of the characteristics of PNS relief looking at the time necessary for PNS to provide relief (washin) and for pain to return after the stimulator was turned off (wash-out). The mean wash-in time was just under $3 \mathrm{~h}$, with a range from the immediate onset of relief in 2 of 11 patients to $8 \mathrm{~h}$. The mean time for pain to return after turning off the stimulator was about $5.5 \mathrm{~h}$, with immediate return of pain in one patient and a range between 1 and $24 \mathrm{~h}$ in the remaining patients. Finch et al. also performed quantitative sensory testing (QST). Unlike changes in VAS with turning the device on or off, there was 
no change in most QST parameters. This finding suggests that conduction blockade is not the primary mechanism by which PNS works, although, given that in a small minority of patients both pain relief and loss of pain relief can occur immediately, conduction blockade may be at work in this subset. Finch et al. hypothesize that the primary mode of action may be either modulation of input into the central nervous system or central sensitization.

Ristic and Ellrich found that PNS modulated the pain threshold [149]. Zhang showed that high-frequency stimulation over $6000 \mathrm{~Hz}$ can, in differing models, lead to either constant activation of potassium channels or the inactivation of sodium channels [150], supporting the conduction blockade. Yang et al. showed that PNS suppresses wind-up of wide-dynamicrange neurons and that PNS differs from spinal cord stimulation in that it does not induce a $\mathrm{C}$-component response in the wide-dynamicrange neurons [151].

Currently, Wall and Melzack's gate theory of pain is considered the most likely explanation for the mode of action of PNS, with orthodromic stimulation of large fibers leading to inhibition of pain transmission through the dorsal horn [88, 152]. Further research is needed to confirm the mechanism of action of PNS. Recent industry-funded reviews have looked to both peripheral and central mechanisms and to the role of large-diameter afferent fibers $[153,154]$.

Despite all that we know about the mechanism of action, PNS technology is continually evolving from peripheral implantation to newer-design wireless miniature wearables. While it is imperative to identify patients who may benefit from PNS stimulation, we must also define what success with the technology looks like. We postulate that outcomes are not sufficient, and advocate rather for identifying which patients may benefit earlier in their treatment course and with which stimulation parameters and neural targets. As these technologies continue to become more and more minimally invasive wearables, pain physicians ought to consider these treatment options earlier in the pain continuum rather than an option of last resort. We anticipate that the use of PNS will grow as more studies are completed and indications are expanded.

\section{LIMITATIONS}

Despite having been used for over 50 years, PNS has a paucity of high-quality literature supporting its use. Of the literature reviewed, only one study was of high quality. Some indications which are currently generating much clinical interest, such as the treatment of joint pain from osteoarthritis, have limited literature supporting their use. Since 2013, there has been increased interest in PNS. The modality requires further documentation of its effectiveness and expansion of its indications in order to become more widely accepted.

The studies reviewed also lack sufficient homogeneity to support a meta-analysis.

\section{CONCLUSION}

PNS was the first application of neuromodulation. Initially, cuff leads encircling the nerve were used, then paddle leads. Both approaches were limited by the need for surgical exposure of the nerve and attendant complications. With the development of cylindrical percutaneous leads that can be placed with either fluoroscopic or ultrasound guidance and powered without the need for a lead to cross a joint, PNS is undergoing a resurgence.

While the vast majority of the reviewed studies were of small samples, collectively they reveal significant improvement in pain utilizing PNS for treatment of neuropathic pain conditions. The best studied application is refractory neuropathic pain involving a peripheral nerve, an indication which has level II evidence.

Cluster headaches and pelvic pain treated with tibial nerve stimulation have level III evidence.

The mechanism of action of PNS is unclear but currently is felt to be related to large-fiber activation, as described by Wall and Melzack's gate control theory. There is also evidence conduction blockade may be involved. 
Further research on the efficacy of therapy and on the mode of action will help expand the applications of PNS.

\section{ACKNOWLEDGEMENTS}

We would like to thank the staff of Pain and Therapy for their assistance and the editorial board of Pain and Therapy for their review and criticism in improving the manuscript.

Funding. No funding or sponsorship was received for this study or publication of this manuscript.

Authorship. All named authors meet the International Committee of Medical Journal Editors (ICMJE) criteria for authorship for this article, take responsibility for the integrity of the work as a whole, and have given their approval for this version to be published.

Authors' Contributions. All authors contributed to the study conception and design. Material preparation, data collection and analysis were performed by Standiford Helm, MD, Andrea Trescot, MD, Shalini Shah, MD, Aaron Calodney, MD, Alaa Abd-Elsayed, MD, MPH, David Kloth, MD, Amol Soin, MD, and Nikita Shirsat. The first draft of the manuscript was written by Standiford Helm, MD, and all authors commented on previous versions of the manuscript. All authors read and approved the final manuscript.

Disclosures. Standiford Helm, MD, is a shareholder in StimWave. Nikita Shirsat has no conflict. Aaron Calodney, MD, is a consultant for Medtronic, Stryker, Nevro and Boston Scientific. Alaa Abd-Elsayed, MD, MPH, is a consultant for Medtronic, StimWave and Avanos. David Kloth, MD, is a consultant and on the medical advisory boards for StimWave and Boston Scientific, is a shareholder in StimWave, and is a Senior Advisor to the NANS Advocacy and Policy Committee. Amol Soin, MD, has an equity position in Soin Neuroscience, does clinical research for Avanos and Neuronoff, and has patents with Avanos and Soin Neuroscience. Shalini Shah, MD MBA, is a consultant for SPR Therapeutics, Allergan, Inc., and Masimo Corporation. Andrea Trescot, MD, is Medical Director for StimWave.

Compliance with Ethics Guidelines. This article is based on previously conducted studies and does not contain any new studies with human participants or animals performed by any of the authors.

Open Access. This article is licensed under a Creative Commons Attribution-NonCommercial 4.0 International License, which permits any non-commercial use, sharing, adaptation, distribution and reproduction in any medium or format, as long as you give appropriate credit to the original author(s) and the source, provide a link to the Creative Commons licence, and indicate if changes were made. The images or other third party material in this article are included in the article's Creative Commons licence, unless indicated otherwise in a credit line to the material. If material is not included in the article's Creative Commons licence and your intended use is not permitted by statutory regulation or exceeds the permitted use, you will need to obtain permission directly from the copyright holder. To view a copy of this licence, visit http://creativecommons.org/licenses/bync/4.0/.

\section{REFERENCES}

1. Goldthwait JE. The lumbo-sacral articulation; an explanation of many cases of "lumbago," "sciatica" and paraplegia. Boston Med Surg J. 1911;164: 365-72.

2. Mixter WJ, Barr JS. Rupture of the intervertebral disc with involvement of the spinal canal. N Engl J Med. 1934;211:210-21.

3. Kuslich SD, Ulstrom CL, Michael CJ. The tissue origin of low back pain and sciatica: a report of pain response to tissue stimulation during operations on the lumbar spine using local anesthesia. Orthop Clin North Am. 1991;22:181-7. 
4. Bonica JJ. The management of pain. Philadelphia: Lea \& Febiger; 1953.

5. Moore D. Regional block: a handbook for use in the clinical practice of medicine and surgery. Springfield: Charles C Thomas; 1953.

6. Trescot AM, Abipp F. Peripheral nerve entrapments: clinical diagnosis and management. Springer; 2016.

7. Wall PD, Sweet WH. Temporary abolition of pain in man. Science. 1967;155:108-9.

8. Melzack R, Wall PD. Pain mechanisms: a new theory. Science. 1965;150:971-9.

9. Shealy CN, Mortimer JT, Reswick JB. Electrical inhibition of pain by stimulation of the dorsal columns: preliminary clinical report. Anesth Analg. 1967;46:489-91.

10. Slavin KV. History of peripheral nerve stimulation, peripheral nerve stimulation. Karger Publishers; 2011. p. 1-15.

11. Weiner RL, Reed KL. Peripheral neurostimulation for control of intractable occipital neuralgia. Neuromudul Technol Neural Interface. 1999;2:217-21.

12. Perryman LT. Neural stimulator system. In: Office USPaT (ed). United States Patent and Trademark Office, 2012.

13. Deer TR, Levy RM, Rosenfeld EL. Prospective clinical study of a new implantable peripheral nerve stimulation device to treat chronic pain. Clin J Pain. 2010;26:359-72.

14. Deer TR, Jain S, Hunter C, et al. Neurostimulation for intractable chronic pain. Brain Sci. 2019;9:23.

15. Manchikanti L, Falco FJE, Singh V, et al. An Update of comprehensive evidence-based guidelines for interventional techniques in chronic spinal pain. Part I: introduction and general considerations. Pain Physician. 2013;16:S1-48.

16. Manchikanti L, Abdi S, Atluri S, et al. An update of comprehensive evidence-based guidelines for interventional techniques in chronic spinal pain. Part II: guidance and recommendations. Pain Physician. 2013;16:S49-283.

17. Manchikanti L. Evidence-based medicine, systematic reviews, and guidelines in interventional pain management, part I: introduction and general considerations. Pain Physician. 2008;11:161-86.

18. Manchikanti L, Hirsch JA, Smith HS. Evidencebased medicine, systematic reviews, and guidelines in interventional pain management: part 2: randomized controlled trials. Pain Physician. 2008;11:717-73.

19. Manchikanti L, Benyamin RM, Helm S, et al. Evidence-based medicine, systematic reviews, and guidelines in interventional pain management: Part 3: systematic reviews and meta-analyses of randomized trials. Pain Physician. 2009;12:35-72.

20. Manchikanti L, Singh V, Smith HS, et al. Evidencebased medicine, systematic reviews, and guidelines in interventional pain management: part 4: observational studies. Pain Physician. 2009;12:73-108.

21. Manchikanti L, Derby R, Wolfer LR, et al. Evidencebased medicine, systematic reviews, and guidelines in interventional pain management: part 5. Diagnostic accuracy studies. Pain Physician. 2009;12: 517-40.

22. Manchikanti L, Datta S, Smith HS, et al. Evidencebased medicine, systematic reviews, and guidelines in interventional pain management: part 6. Systematic reviews and meta-analyses of observational studies. Pain Physician. 2009;12:819-50.

23. Manchikanti L, Derby R, Wolfer L, et al. Evidencebased medicine, systematic reviews, and guidelines in interventional pain management: Part 7: systematic reviews and meta-analyses of diagnostic accuracy studies. Pain Physician. 2009;12:929-63.

24. Liberati A, Altman DG, Tetzlaff J, et al. The PRISMA statement for reporting systematic reviews and meta-analyses of studies that evaluate health care interventions: explanation and elaboration. Ann Intern Med. 2009;151:W1-30.

25. van Tulder M, Furlan A, Bombardier C, et al. Updated method guidelines for systematic reviews in the Cochrane collaboration back review group. Spine. 2003;28:1290-9.

26. Furlan AD, Pennick V, Bombardier C, et al. 2009 updated method guidelines for systematic reviews in the Cochrane Back Review Group. Spine (Phila Pa 1976). 2009;34:1929-41.

27. Manchikanti L, Singh V, Helm S, et al. An introduction to an evidence-based approach to interventional techniques in the management of chronic spinal pain. Pain Physician. 2009;12:E1-33.

28. Guyatt GH, Oxman AD, Vist GE, et al. GRADE: an emerging consensus on rating quality of evidence and strength of recommendations. BMJ. 2008;336: 924-6.

29. Morton S, Berg A, Levit L, et al. Finding what works in health care: standards for systematic reviews: committee on standards for systematic reviews of 
comparative effectiveness research. Institute of Medicine, National Academies Press; 2011.

30. Methods guide for effectiveness and comparative effectiveness reviews. Rockville: Agency for Healthcare Research and Quality; 2017.

31. Local coverage determination (LCD): peripheral nerve and peripheral nerve field stimulation (L34328). Noridian Healthcare Solutions, LLC; 2017.

32. Plaza-Manzano G, Gómez-Chiguano GF, Cleland JA, et al. Effectiveness of percutaneous electrical nerve stimulation for musculoskeletal pain: a systematic review and meta-analysis. Eur J Pain. 2020;24:1023-44.

33. National coverage determination (NCD) for assessing patient's suitability for electrical nerve stimulation therapy (160.7.1). Centers for Medicare and Medicaid Services; 2006.

34. Chen Y-F, Bramley G, Unwin G, et al. Occipital nerve stimulation for chronic migraine-a systematic review and meta-analysis. PLOS ONE. 2015;10: e0116786.

35. Sweet JA, Mitchell LS, Narouze S, et al. Occipital nerve stimulation for the treatment of patients with medically refractory occipital neuralgia: congress of neurological surgeons systematic review and evidence-based guideline. Neurosurgery. 2015;77: 332-41.

36. Yang Y, Song M, Fan Y, et al. Occipital nerve stimulation for migraine: a systematic review. Pain Pract. 2016;16:509-17.

37. Tang Y, Kang J, Zhang Y, et al. Influence of greater occipital nerve block on pain severity in migraine patients: a systematic review and meta-analysis. Am J Emerg Med. 2017;35:1750-4.

38. Ducic I, Felder JM, Fantus SA. A systematic review of peripheral nerve interventional treatments for chronic headaches. Ann Plast Surg. 2014;72:439-45.

39. Cadalso RT, Daugherty J, Holmes C, et al. Efficacy of electrical stimulation of the occipital nerve in intractable primary headache disorders: a systematic review with meta-analyses. J Oral Facial Pain Headache. 2018;32:40-52.

40. Cottin SC, Gallani N, Cantin L, et al. Occipital nerve stimulation for non-migrainous chronic headaches: a systematic review protocol. Syst Rev. 2019;8:181.

41. Gaziev G, Topazio L, Iacovelli V, et al. Percutaneous tibial nerve stimulation (PTNS) efficacy in the treatment of lower urinary tract dysfunctions: a systematic review. BMC Urol. 2013;13:1-11.
42. Cottrell AM, Schneider MP, Goonewardene S, et al. Benefits and harms of electrical neuromodulation for chronic pelvic pain: a systematic review. Eur Urol Focus. 2020;6:559-71.

43. Beckman Michael SS. Pudendal peripheral nerve stimulation. In: Trescot Andrea A-E, Alaa, editors. Peripheral nerve stimulation. New York: Elsevier; 2021.

44. Deer TR, Grider JS, Lamer TJ, et al. A systematic literature review of spine neurostimulation therapies for the treatment of pain. Pain Med. 2020;21: 1590-603.

45. Xu J, Sun Z, Wu J, et al. Peripheral nerve stimulation in pain management: a systematic review. Pain Physician. 2021;24:E131-52.

46. Deer TR, Esposito MF, McRoberts WP, et al. A systematic literature review of peripheral nerve stimulation therapies for the treatment of pain. Pain Med. 2020;21:1590-603.

47. Manchikanti L, Hirsch JA, Cohen SP, et al. Assessment of methodologic quality of randomized trials of interventional techniques: development of an interventional pain management specific instrument. Pain Physician. 2014;17:E263-90.

48. Manchikanti L, Hirsch JA, Heavner J, et al. Development of an interventional pain management specific instrument for methodologic quality assessment of nonrandomized studies of interventional techniques. Pain Physician. 2014;17: E291-317.

49. Djulbegovic B, Guyatt GH. Evidence vs consensus in clinical practice guidelines. JAMA. 2019. [published Online First: 07/19/2019].

50. Hagg O, Fritzell P, Nordwall A. The clinical importance of changes in outcome scores after treatment for chronic low back pain. Eur Spine J. 2003;12: 12-20.

51. Laursen B, Bajaj P, Olesen A, et al. Health related quality of life and quantitative pain measurement in females with chronic non-malignant pain. Eur J Pain. 2005;9:267-75.

52. Farrar JT, Portenoy RK, Berlin JA, et al. Defining the clinically important difference in pain outcome measures. Pain. 2000;88:287-94.

53. Salaffi F, Stancati A, Silvestri CA, et al. Minimal clinically important changes in chronic musculoskeletal pain intensity measured on a numerical rating scale. Eur J Pain. 2004;8:283-91. 
54. Andersson GBJ. Editorial: epidural glucocorticoid injections in patients with lumbar spinal stenosis. NEJM. 2014;371:75-6.

55. Amirdelfan K, Gliner BE, Kapural L, et al. A proposed definition of remission from chronic pain, based on retrospective evaluation of 24-month outcomes with spinal cord stimulation. Postgrad Med. 2019;131:278-86.

56. Lohr KN, Carey TS. Assessing "best evidence": issues in grading the quality of studies for systematic reviews. Jt Comm J Qual Improv. 1999;25:470-9.

57. Clarke M, Oxman A. Cochrane reviewers handbook 4.0 [Updated July 1999] In: Review Manager (RevMan) (Computer Program), Version 4.0. Oxford: The Cochrane Collaboration; 1999.

58. How to use the evidence: assessment and application of scientific evidence. National Health and Medical Research Council Canberra; 2000.

59. van Tulder MW, Koes BW, Bouter LM. Conservative treatment of acute and chronic nonspecific low back pain. A systematic review of randomized controlled trials of the most common interventions. Spine. 1997;22:2128-56.

60. Harris RP, Helfand M, Woolf SH, et al. Current methods of the US preventive services task force: a review of the process. Am J Prev Med. 2001;20: 21-35.

61. Guyatt GH, Cook DJ, Jaeschke R, et al. Grades of recommendation for antithrombotic agents: American College of Chest Physicians evidence-based clinical practice guidelines (8th edition). Chest. 2008;133:S123-31.

62. Gray JAM. Evidence-based healthcare and public health: how to make decisions about health services and public health. Elsevier Health Sciences; 2009.

63. Liberati A, Altman DG, Tetzlaff J, et al. The PRISMA statement for reporting systematic reviews and meta-analyses of studies that evaluate health care interventions: explanation and elaboration. Ann Intern Med. 2009;151:W-65-W-94.

64. Deer T, Pope J, Benyamin R, et al. Prospective, multicenter, randomized, double-blinded, partial crossover study to assess the safety and efficacy of the novel neuromodulation system in the treatment of patients with chronic pain of peripheral nerve origin. Neuromodul Technol Neural Interface. 2016;19:91-100.

65. Finch P, Price L, Drummond P. High-frequency (10 $\mathrm{kHz}$ ) electrical stimulation of peripheral nerves for treating chronic pain: a double-blind trial of presence vs absence of stimulation. Neuromodul Technol Neural Interface. 2019;22:529-36.

66. Oswald J, Shahi V, Chakravarthy KV. Prospective case series on the use of peripheral nerve stimulation for focal mononeuropathy treatment. Pain Manag. 2019;9:551-8.

67. Kurklinsky S, Palmer SC, Arroliga MJ, et al. Neuromodulation in postherpetic neuralgia: case reports and review of the literature. Pain Med. 2018;19: 1237-44.

68. Mansfield JT, Desai MJ. Axillary peripheral nerve stimulation for chronic shoulder pain: a retrospective case series. Neuromodul Technol Neural Interface. $2020 ; 23: 812-8$.

69. Langford B, Mauck WD. Advancement in neuromodulation technology with the innovation of design-specific peripheral nerve stimulators: sural nerve stimulation for radiculopathy. Pain Med. 2020;21:1297-300.

70. Martin S, Han E, Peters KM. A novel approach to managing post retropubic vaginal sling pain. Urology. 2020;137:196-9.

71. Colini Baldeschi G, Dario A, De Carolis G, et al. Peripheral nerve stimulation in the treatment of chronic pain syndromes from nerve injury: a multicenter observational study. Neuromodul Technol Neural Interface. 2017;20:369-74.

72. Wilson RD, Bennett ME, Nguyen VQ, et al. Fully implantable peripheral nerve stimulation for hemiplegic shoulder pain: a multi-site case series with two-year follow-up. Neuromodul Technol Neural Interface. 2018;21:290-5.

73. Dewandre Q, Dubuisson A, Kaschten B, et al. Refractory neuropathic pain from a median nerve injury: spinal cord or peripheral nerve stimulation? A case report. Acta Neurol Belg. 2020;120:867-71. https://doi.org/10.1007/s13760-018-01065-4.

74. Bouche B, Manfiotto M, Rigoard P, et al. Peripheral nerve stimulation of brachial plexus nerve roots and supra-scapular nerve for chronic refractory neuropathic pain of the upper limb. Neuromodul Technol Neural Interface. 2017;20:684-9.

75. Freitas TDS, Fonoff ET, Marquez Neto OR, et al. Peripheral nerve stimulation for painful mononeuropathy secondary to leprosy: a 12-month followup study. Neuromodul Technol Neural Interface. 2018;21:310-6.

76. Manzi S, Abd-Elsayed A, Vanquathem N. Peripheral nerve stimulation of the suprascapular nerve for treatment of shoulder pain. Chronic Pain Manag. 
2019;3:120. https://doi.org/10.29011/2576-957X. 100020 .

77. Sokal P, Harat M, Zieliński P, et al. Tibial nerve stimulation with a miniature, wireless stimulator in chronic peripheral neuropathic pain. J Pain Res. 2017;10:613.

78. Abd-Elsayed A. Wireless peripheral nerve stimulation for treatment of peripheral neuralgias. Neuromodul Technol Neural Interface. 2020. [published Online First: 3/3/2020].

79. Novak CB, Mackinnon SE. Outcome following implantation of a peripheral nerve stimulator in patients with chronic nerve pain. Plast Reconstr Surg. 2000;105:1967-72.

80. Rauck RL, Cohen SP, Gilmore CA, et al. Treatment of post-amputation pain with peripheral nerve stimulation. Neuromodul Technol Neural Interface. 2014;17:188-97.

81. Van Calenbergh F, Gybels J, Van Laere K, et al. Long term clinical outcome of peripheral nerve stimulation in patients with chronic peripheral neuropathic pain. Surg Neurol. 2009;72:330-5.

82. Kouroukli I, Neofytos D, Panaretou V, et al. Peripheral subcutaneous stimulation for the treatment of intractable postherpetic neuralgia: two case reports and literature review. Pain Pract. 2009;9: 225-9.

83. Yakovlev A, Karasev SA, Dolgich OY. Sacral nerve stimulation: a novel treatment of chronic anal fissure. Dis Colon Rectum. 2011;54:324-7.

84. Reverberi C, Dario A, Barolat G, et al. Using peripheral nerve stimulation (PNS) to treat neuropathic pain: a clinical series. Neuromodul Technol Neural Interface. 2014;17:777-83.

85. Ruiz-Tovar J, Llavero C. Percutaneous posterior tibial nerve stimulation vs perianal application of glyceryl trinitrate ointment in the treatment of chronic anal fissure: a randomized clinical trial. Dis Colon Rectum. 2017;60:81-6.

86. Oberoi J, Sampson C, Ross E. Head and neck peripheral stimulation for chronic pain report of three cases. Neuromodul Technol Neural Interface. 2008;11:272-6.

87. Cohen SP, Gilmore CA, Rauck RL, et al. Percutaneous peripheral nerve stimulation for the treatment of chronic pain following amputation. Mil Med. 2019;184:e267-74.

88. Gilmore CA, Ilfeld BM, Rosenow JM, et al. Percutaneous 60-day peripheral nerve stimulation implant provides sustained relief of chronic pain following amputation: 12-month follow-up of a randomized, double-blind, placebo-controlled trial. Reg Anesth Pain Med. 2020;45:44-51.

89. Jeon IC, Kim MS, Kim SH. Median nerve stimulation in a patient with complex regional pain syndrome type II. J Korean Neurosurg Soc. 2009;46: 273.

90. Rosenow JM, Gilmore C, Ilfeld BM, et al. One year follow-up of a randomized, double-blind, placebocontrolled trial of percutaneous peripheral nerve stimulation for chronic neuropathic pain following amputation. Neurosurgery. 2019;66:nyz310_144.

91. Eisenberg E, Waisbrod H, Gerbershagen HU. Longterm peripheral nerve stimulation for painful nerve injuries. Clin J Pain. 2004;20:143-5.

92. Narouze SN, Zakari A, Vydyanathan A. Ultrasoundguided placement of a permanent percutaneous femoral nerve stimulator leads for the treatment of intractable femoral neuropathy. Pain Physician. 2009;12:E305-8.

93. Gilmore CA, Kapural L, McGee MJ, et al. Percutaneous peripheral nerve stimulation (PNS) for the treatment of chronic low back pain provides sustained relief. Neuromodul Technol Neural Interface. 2019;22:615-20.

94. Gilmore C, Ilfeld B, Rosenow J, et al. Percutaneous peripheral nerve stimulation for the treatment of chronic neuropathic postamputation pain: a multicenter, randomized, placebo-controlled trial. Reg Anesth Pain Med. 2019;44:637-45.

95. García-Bermejo P, De-la-Cruz-Torres B, RomeroMorales C. Ultrasound-guided percutaneous neuromodulation in patients with unilateral anterior knee pain: a randomized clinical trial. Appl Sci. 2020;10:4647.

96. Mainkar O, Sollo CA, Chen G, et al. Pilot study in temporary peripheral nerve stimulation in oncologic pain. Neuromodul Technol Neural Interface. 2020. [published Online First: 3/17/20]

97. Gilmore CA, Kapural L, McGee MJ, et al. Percutaneous peripheral nerve stimulation for chronic low back pain: prospective case series with 1 year of sustained relief following short-term implant. Pain Pract. 2020;20:310-20.

98. Campbell JN, Long DM. Peripheral nerve stimulation in the treatment of intractable pain. J Neurosurg. 1976;45:692-9.

99. Hassenbusch SJ, Stanton-Hicks M, Schoppa D, et al. Long-term results of peripheral nerve stimulation for reflex sympathetic dystrophy. J Neurosurg. 1996;84:415-23. 
100. Huntoon MA, Burgher AH. Ultrasound-guided permanent implantation of peripheral nerve stimulation (PNS) system for neuropathic pain of the extremities: original cases and outcomes. Pain Med. 2009;10:1369-77.

101. Burgher AH, Huntoon MA, Turley TW, et al. Subcutaneous peripheral nerve stimulation with interlead stimulation for axial neck and low back pain: case series and review of the literature. Neuromodul Technol Neural Interface. 2012;15:100-7.

102. Goroszeniuk T. The effect of peripheral neuromodulation on pain from the sacroiliac joint: a retrospective cohort study. Neuromodul Technol Neural Interface. 2019;22:661-6.

103. Strege DW, Cooney WP, Wood MB, et al. Chronic peripheral nerve pain treated with direct electrical nerve stimulation. J Hand Surg. 1994;19:931-9.

104. Mobbs RJ, Nair S, Blum P. Peripheral nerve stimulation for the treatment of chronic pain. J Clin Neurosci. 2007;14:216-21.

105. Verrills P, Vivian D, Mitchell B, et al. Peripheral nerve field stimulation for chronic pain: 100 cases and review of the literature. Pain Med. 2011;12: 1395-405.

106. Yakovlev AE, Peterson AT. Peripheral nerve stimulation in treatment of intractable postherpetic neuralgia. Neuromodulation. 2007;10:373-5.

107. Billet B, Wynendaele R, Vanquathem NE. A novel minimally invasive wireless technology for neuromodulation via percutaneous intercostal nerve stimulation for post-herpetic neuralgia: a case report with short-term follow-up. Pain Pract. 2018;18:374-9.

108. Herschkowitz D, Kubias J. A case report of wireless peripheral nerve stimulation for complex regional pain syndrome type-I of the upper extremity: 1 year follow up. Scand J Pain. 2019;19. [published Online First: 8/23/19].

109. Elahi F, Reddy CG. Neuromodulation of the suprascapular nerve. Pain Physician. 2014;17: E769-73.

110. Kurt E, van Eijk T, Henssen D, et al. Neuromodulation of the suprascapular nerve. Pain Physician. 2016:E235-E239.

111. Waisbrod H, Hansen D, Panhans $\mathrm{CH}$, et al. Direct nerve stimulation for painful traumatic peripheral neuropathies. Pain. 1984;18:S118.

112. Picaza JA, Cannon BW, Hunter SE, et al. Pain suppression by peripheral nerve stimulation. Part II.
Observations with implanted devices. Surg Neurol. $1975 ; 4: 115-26$.

113. Picaza JA, Hunter SE, Cannon BW. Pain suppression by peripheral nerve stimulation. Appl Neurophysiol. $1977 ; 40: 223-34$.

114. Cauthen JC, Renner EJ. Transcutaneous and peripheral nerve stimulation for chronic pain states. Surg Neurol. 1975;4:102-4.

115. Sweet WH. Control of pain by direct electrical stimulation of peripheral nerves. Neurosurgery. 1975;23:103-11.

116. Law JD, Swett J, Kirsch WM. Retrospective analysis of 22 patients with chronic pain treated by peripheral nerve stimulation. J Neurosurg. 1980;52:482-5.

117. Wilson RD, Harris MA, Gunzler DD, et al. Percutaneous peripheral nerve stimulation for chronic pain in subacromial impingement syndrome: a case series. Neuromodulation. 2014;17(8):771-6. https:// doi.org/10.1111/ner.12152.

118. Lepski G, Vahedi P, Tatagiba MS, et al. Combined spinal cord and peripheral nerve field stimulation for persistent post-herniorrhaphy pain. Neuromodul Technol Neural Interface. 2013;16:84-9.

119. Hahn L. Treatment of ilioinguinal nerve entrapment-a randomized controlled trial. Acta Obstet Gynecol Scand. 2011;90:955-60.

120. Billet B, Wynendaele R, Vanquathem NE. Wireless neuromodulation by a minimally invasive technique for chronic refractory pain. Report of preliminary observations. Med Res Arch. 2017:5.

121. Van Balken MR, Vandoninck V, Messelink BJ, et al. Percutaneous tibial nerve stimulation as neuromodulative treatment of chronic pelvic pain. Eur Urol. 2003;43:158-63.

122. Vaisman J, Markley HT, Ordia J, et al. The treatment of medically intractable trigeminal autonomic cephalalgia with supraorbital/supratrochlear stimulation: a retrospective case series. Neuromodulation. 2012;15:374-80.

123. Stevanato G, Devigili G, Eleopra R, et al. Chronic post-traumatic neuropathic pain of brachial plexus and upper limb: a new technique of peripheral nerve stimulation. Neurosurg Rev. 2014;37:473-80.

124. Dunteman E. Peripheral nerve stimulation for unremitting ophthalmic postherpetic neuralgia. Neuromodul Technol Neural Interface. 2002;5: 32-7.

125. Johnson MD, Burchiel KJ. Peripheral stimulation for treatment of trigeminal postherpetic neuralgia and 
trigeminal posttraumatic neuropathic pain: a pilot study. Neurosurgery. 2004;55:135-42.

126. Lerman IR, Chen JL, Hiller D, et al. Novel highfrequency peripheral nerve stimulator treatment of refractory postherpetic neuralgia: a brief technical note. Neuromodul Technol Neural Interface. 2015;18:487-93.

127. Soin A, Syed Shah N, Fang ZP. High-frequency electrical nerve block for postamputation pain: a pilot study. Neuromodul Technol Neural Interface. 2015;18:197-206.

128. Eldabe SS, Taylor RS, Goossens S, et al. A Randomized controlled trial of subcutaneous nerve stimulation for back pain due to failed back surgery syndrome: the SubQStim study. Neuromodul Technol Neural Interface. 2019;22:519-28.

129. van Gorp EJJ, Teernstra OP, Gültuna I, et al. Subcutaneous stimulation as ADD-ON therapy to spinal cord stimulation is effective in treating low back pain in patients with failed back surgery syndrome: a multicenter randomized controlled trial. Neuromodul Technol Neural Interface. 2016;19:171-8.

130. McRoberts WP, Wolkowitz R, Meyer DJ, et al. Peripheral nerve field stimulation for the management of localized chronic intractable back pain: results from a randomized controlled study. Neuromodul Technol Neural Interface. 2013;16:565-75.

131. Schoenen J, Jensen RH, Lanteri-Minet $M$, et al. Stimulation of the sphenopalatine ganglion (SPG) for cluster headache treatment. Pathway $\mathrm{CH}-1$ : a randomized, sham-controlled study. Cephalalgia. 2013;33:816-30.

132. Wilson R, Gunzler D, Bennett M, et al. Peripheral nerve stimulation compared with usual care for pain relief of hemiplegic shoulder pain: a randomized controlled trial (Erratum vol 95, pg E29, 2016). Am J Phys Med Rehabil. 2014;93:17-28.

133. Wilson RD, Knutson JS, Bennett ME, et al. The effect of peripheral nerve stimulation on shoulder biomechanics: a randomized controlled trial in comparison to physical therapy. Am J Phys Med Rehabil. 2017;96:191.

134. Gokyildiz S, Beji NK, Yalcin O, et al. Effects of percutaneous tibial nerve stimulation therapy on chronic pelvic pain. Gynecol Obstet Invest. 2012;73:99-105.

135. Istek A, Ugurlucan FG, Yasa C, et al. Randomized trial of long-term effects of percutaneous tibial nerve stimulation on chronic pelvic pain. Arch Gynecol Obstet. 2014;290:291-8.
136. Kabay S, Kabay SC, Yucel M, et al. Efficiency of posterior tibial nerve stimulation in category IIIB chronic prostatitis/chronic pelvic pain: a ShamControlled Comparative Study. Urol Int. 2009;83: 33-8.

137. Chae J, David TY, Walker ME, et al. Intramuscular electrical stimulation for hemiplegic shoulder pain: a 12-month follow-up of a multiple-center, randomized clinical trial. Am J Phys Med Rehabil. 2005;84:832-42.

138. Chmiela MA, Hendrickson M, Hale J, et al. Direct peripheral nerve stimulation for the treatment of complex regional pain syndrome: a 30-year review. Neuromodulation. 2020. https://doi.org/10.1111/ ner.13295.

139. Amorizzo E, Colini-Baldeschi G. Peripheral nerve stimulation: two cases of intractable neuropathic pain. Anesth Pain Med. 2021;11(2):e113162. https://doi.org/10.5812/aapm.113162.

140. Deer TR, Gilmore CA, Desai MJ, et al. Percutaneous peripheral nerve stimulation of the medial branch nerves for the treatment of chronic axial back pain in patients after radiofrequency ablation. Pain Med. 2021;22:548-60.

141. Frederico TN, da Silva FT. Peripheral nerve stimulation of the brachial plexus for chronic refractory crps pain of the upper limb: description of a new technique and case series. Pain Med. 2020;21: S18-26.

142. Warner NS, Schaefer KK, Eldrige JS, et al. Peripheral nerve stimulation and clinical outcomes: a retrospective case series. Pain Pract. 2021;21:411-8.

143. Harden RN, Bruehl S, Stanton-Hicks M, et al. Proposed new diagnostic criteria for complex regional pain syndrome. Pain Med. 2007;8:326-31.

144. Ishizuka K, Oaklander AL, Chiocca EA. A retrospective analysis of reasons for reoperation following initially successful peripheral nerve stimulation. J Neurosurg. 2007;106:388-90.

145. McJunkin T, Lynch P, Srejic E. Complications of peripheral nerve stimulation: open technique, percutaneous technique, and peripheral nerve field stimulation. In: Reducing risks and complications of interventional pain procedures. Philadelphia: Elsevier Saunders; 2012.

146. Eldabe S, Buchser E, Duarte RV. Complications of spinal cord stimulation and peripheral nerve stimulation techniques: a review of the literature. Pain Med. 2016;17:325-36.

147. Choi SC, Chae JS, Kim YJ, et al. Lead fracture of peripheral nerve stimulator for brachial 
plexopathy-a case report. Korean J Anesthesiol. 2018;71:407.

148. Deer TR, Pope JE, Kaplan M. A novel method of neurostimulation of the peripheral nervous system: the StimRouter implantable device. Tech Reg Anesth Pain Manag. 2012;16:113-7.

149. Ristić D, Ellrich J. Innocuous peripheral nerve stimulation shifts stimulus-response function of painful laser stimulation in man. Neuromodul Technol Neural Interface. 2014;17:686-95.

150. Zhang X, Roppolo JR, De Groat WC, et al. Mechanism of nerve conduction block induced by highfrequency biphasic electrical currents. IEEE Trans Biomed Eng. 2006;53:2445-54.
151. Yang F, Xu Q, Cheong YK, et al. Comparison of intensity-dependent inhibition of spinal wide-dynamic range neurons by dorsal column and peripheral nerve stimulation in a rat model of neuropathic pain. Eur J Pain. 2014;18:978-88.

152. Papuć E, Rejdak K. The role of neurostimulation in the treatment of neuropathic pain. Ann Agric Environ Med. 2013;1:14-7.

153. Lin T, Gargya A, Singh H, et al. Mechanism of peripheral nerve stimulation in chronic pain. Pain Med. 2020;21:S6-12.

154. Deer TR, Eldabe S, Falowski SM, et al. Peripherally induced reconditioning of the central nervous system: a proposed mechanistic theory for sustained relief of chronic pain with percutaneous peripheral nerve stimulation. J Pain Res. 2021;14:721. 